\title{
Just do it:
}

\section{Supporting a world of difference}

\author{
Eileen Diamond, Physiotherapist and \\ Cindy Fox, Occupational therapist work for G.S.E. in Tai Tokerau.
}
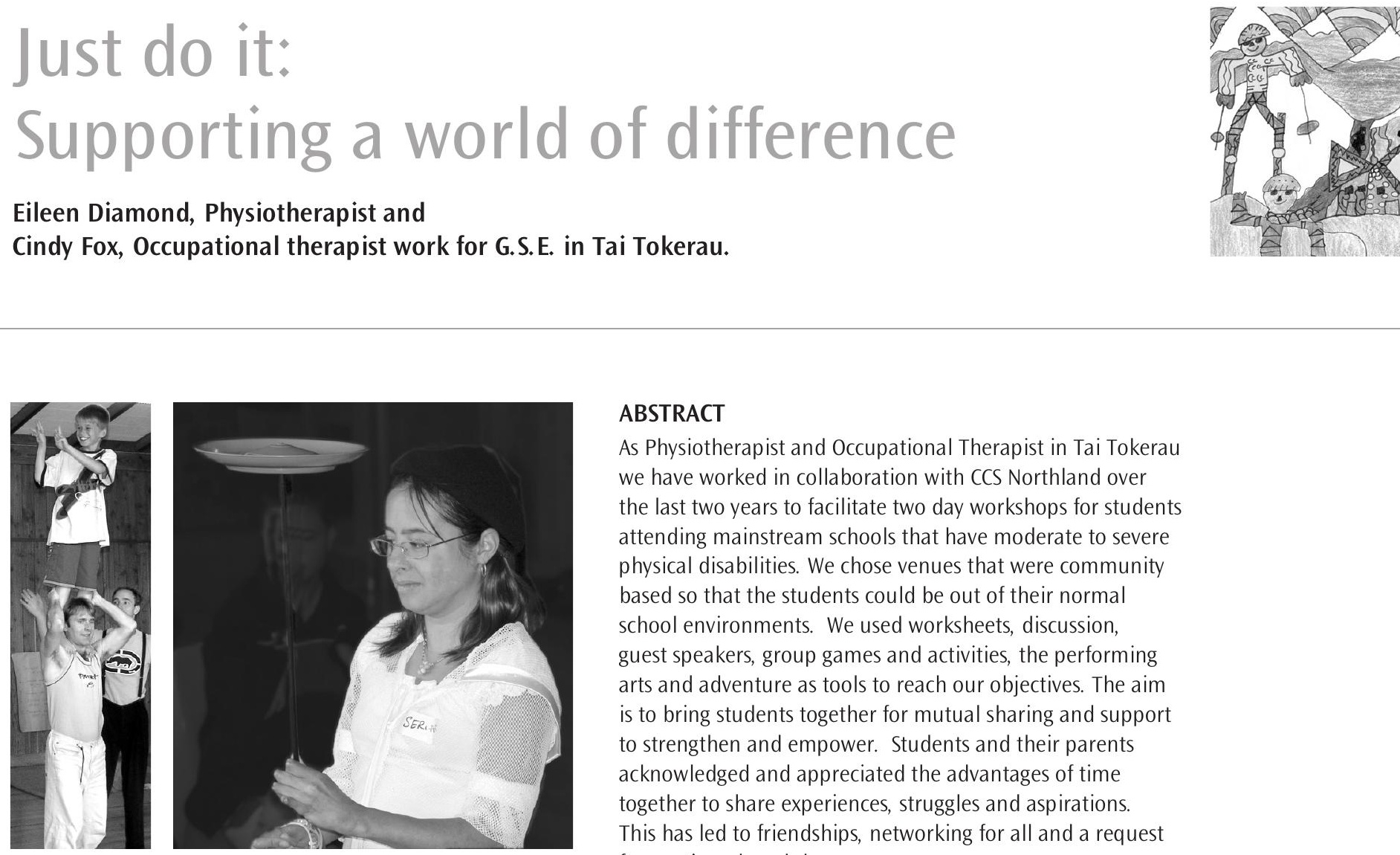

\begin{abstract}
As Physiotherapist and Occupational Therapist in Tai Tokerau we have worked in collaboration with CCS Northland over the last two years to facilitate two day workshops for students attending mainstream schools that have moderate to severe physical disabilities. We chose venues that were community based so that the students could be out of their normal school environments. We used worksheets, discussion, guest speakers, group games and activities, the performing arts and adventure as tools to reach our objectives. The aim is to bring students together for mutual sharing and support to strengthen and empower. Students and their parents acknowledged and appreciated the advantages of time together to share experiences, struggles and aspirations. This has led to friendships, networking for all and a request for continued workshops.

In our roles as Physiotherapist and Occupational Therapist for Special Education we are involved with students in the mainstream schools under the Ongoing Reviewable Resource Scheme (ORRS) and the Moderate Physical Disabilities contract. Our caseload covers a wide spectrum of disorders encompassing congenital abnormalities, global delay and a diversity of syndromes. Our working area covers from Kaiwaka (this is approximately one hours drive north of Auckland,) to the top of the North Island.
\end{abstract}

As therapists we identified a special group of students with physical disabilities because of their motivating attitude to life. These are students who require only intermittent intervention from us as therapists even though they may have quite severe physical disabilities. The young people need support for areas such as accessing the curriculum through Assistive Technology making adaptations to the Physical Education Curriculum and Technology, and having ready access to the classrooms, school and surrounds which necessitate property modifications. Our role in supporting these young people is to facilitate, consult and support this process.

The physical disabilities of this particular group of students includes shortened or absence of limbs or bones, congenital conditions that have resulted in some form of deformity, arthritis or cerebral palsy.

The students are cognitively able and all have supportive parents who are determined that their children will get a good education and make the very best they can out of their lives. One of these parents planted the seed of an idea when 
she mentioned her son (who has cerebral palsy) had enquired if there was any way he could meet up with other students similar to himself. He attends a primary school and felt he was "different" as he was the only child with a physical disability.

The idea materialized into a two-day workshop in March 2003 run collaboratively with CCS Northland. We named the workshop" Just Do It" with the theme of Past, Present and Future Achievements. Our goals for the workshop were primarily to facilitate opportunities to enable the students to:

- make new friends

- meet up with old friends

- learn strategies for coping

- set personal goals

- promote Leadership and mentoring

- have adventure and fun

- develop strategies to overcome hurdles

- meet adults with similar disabilities

- achieve clear learning outcomes in the essential skills area of the New Zealand school curriculum

- increase self esteem \& confidence make the objectives in the NZ Disabilities Strategy happen.

The workshop was designed around giving students an opportunity to share goals. In the first session students spoke about their own past achievements and shared with others what they felt proud of. This included sporting, academic and travelling type achievements.

The second part of the workshop held at the local gym was around current goal setting with the challenge to climb, abseil, swing or assist by belaying (provide rope support) at the climbing wall. Students set their own personal goals which ranged from swinging in the sling to climbing to the top of the wall. This was an incredible time of encouragement and courage as different students aimed to reach their goals. It was noted that students willingly helped one another, they were quick to offer to belay for another student while they climbed. In fact, this was a key activity necessary in the process of climbing the wall and it created great team building and leadership opportunities, empowering and encouraging the students to help each other.

The third session was goal setting for the future. This allowed students to plan and voice their aspirations. For some, their goals were around problem solving current concerns like bullying, learning to swim and for others it was planning for tertiary education and world travel. This process acknowledged the great feeling of hope and ambition for the future within the group.

Two adult guest speakers spoke on life for them with a disability. One explained that it was only as she entered high school she realised she actually had a disability (she was born without lower limbs). The second speaker has a visual impairment and brought her Seeing Eye dog with her and shared how life is as a blind person. The students felt free to talk and ask questions. There were detailed discussions on bullying and strategies on how to cope, employment opportunities, driving and transporting wheelchairs independently in cars.

Direct comments and formal feedback confirmed for us that we had achieved our aims and we had had a fun and successful workshop.

Examples of some comments on the workshop evaluation forms:

- "all of the children were team players and built up relationships on trust and support"

- "to hear what the children perceived as obstacles to achieving their goals-interesting and encouraging"

- "boosted Matt's confidence in just two days, I hope it lasts"

- "it's fun and it is good to meet other people with disabilities"

- "I had fun and I learnt a lot".

Requests from the students participating and their parents resulted in another workshop being one year later, which we named "Just Do It Again."

We had a larger group this time and included most of those who attended in 2003, our aims were similar but we changed our theme to "Celebrating Who We Are" with a focus on the Performing Arts. We invited guests from CCS in Auckland who use puppets in schools to create discussion around disabilities. The students had earlier completed worksheets in groups on what they felt were their own strengths and difficulties. These were used to develop and write possible puppet plays to share with other school students.

Key issues identified through the young people's feedback were:

- being stared at

- being talked over or talked about in earshot

- expectations to do things that would be quite impossible to do

- shyness around lots of people.

The second day was even more interactive and definitely fun and challenging. We had invited a troupe of talented artists (from "Hot spot Productions" based in Dargaville) who demonstrated their skills in acrobatics and juggling. The troupe presented many participatory opportunities. The students set for themselves challenges which were awe inspiring. Some chose to attempt acrobatic feats, others tried juggling; others participated as volunteers while wild juggling displays happened around and over them. They then worked in groups to produce three different dramatic performances entitled, The Past, The Present and The Future. These dramatic performances, along with some of their acrobatic achievements were presented to their parents in the afternoon. 
The success of invited speakers at the first workshop prompted us to select further guest speakers who spoke on life with disabilities. The first was the producer of a radio show that airs views and news items centered on people with disabilities. He spoke of how life is for him with a disability and how he manages to overcome some of his problems and reach his goals. He gave the students an opportunity to be interviewed for his programme giving their views on life to be aired at a later date.

The second speaker was a senior student from one of our local schools. He presented a power point show with the assistance of a school friend. His focus was "Just Doing It" and had many photos of himself participating in challenging situations. He emphasised the value of good friends and a positive attitude. He inspired the students to give everything in life a go. He also discussed the benefits of having a disability and the great opportunities it had given him to travel and meet people, some of them well known celebrities from sports and entertainment.

In summary, all who participated in or observed these two workshops expressed very positive outcomes, some of which were:

- students meeting and sharing with other students

- increasing their self confidence and acceptance of who they are

- networking with other parents and professionals and sharing of concerns

- the opportunity for students to support and exchange experiences

- students from all parts of Northland having the opportunity to meet and develop friendships.

The workshops were developed as a result of a parent listening to the needs of her child and us listening to her. Cindy (Occupational Therapist) and I (Physiotherapist) feel privileged to have had the opportunity to facilitate these. In addition to being great fun and supporting these young people to achieve their goals, we came away from these days with such a "buzz" of how truly special these students are and how proud we are to be part of their community.

Eileen Diamond - Physiotherapist

Cindy Fox - Occupational Therapist

PROFILE OF AUTHORS

Eileen Diamond, Physiotherapist and Cindy Fox, Occupational therapist work for G.S.E. in Tai Tokerau.

Our core work is to support children with physical disabilities access school and the New Zealand Curriculum by removing barriers to their learning. We service a large area, incorporating rural and urban schools. "Just do it" workshops are a way to bring some of these children together to share experiences, make new friends and support each other in their lives. 